\title{
Rethinking Internet skills: The contribution of gender, age, education, Internet experience, and hours online to medium- and content-related Internet skills
}

\author{
Alexander J.A.M. van Deursen ${ }^{a, *}$, Jan A.G.M. van Dijk ${ }^{a}$, Oscar Peters ${ }^{b}$ \\ ${ }^{\text {a } U n i v e r s i t y ~ o f ~ T w e n t e, ~ t h e ~ N e t h e r l a n d s ~}$ \\ ${ }^{\mathrm{b}}$ IBR Research Institute for Social Sciences and Technology, the Netherlands
}

Available online 2 April 2011

\begin{abstract}
This paper focuses on one of the factors that appears to be important in several conceptualizations of how to approach the digital divide: the differential possession of so-called Internet skills. Three largescale performance tests are conducted to reveal the contributions of gender, age, educational level of attainment, Internet experience, and amount of Internet use on both medium- and content-related Internet skills. Age appears to have a negative influence on medium-related skills. However, there is a positive contribution to the level of content-related skills, meaning that older generations perform better than the younger. Unfortunately, they are impeded by their low level of medium-related skills in such a way that the actual result is negative. This noteworthy conclusion, to our knowledge, has hardly received any attention in digital divide research. Educational attainment appears significant for both medium- and content-related Internet skills. This conclusion contrasts somewhat with other research that claims that people learn digital skills more in practice than in formal educational settings. Internet experience only contributes to medium-related skills. It appears that content-related skills do not grow with years of Internet experience and the number of hours spent online weekly. The latter only has some effect on medium-related skills.
\end{abstract}

(C) 2011 Elsevier B.V. All rights reserved.

\section{Introduction}

The concept of the digital divide rests on a comparative perspective of relative inequality. The idea behind this concept is that there are significant benefits from computer and Internet usage and

\footnotetext{
* Corresponding author at: University of Twente, Department of Media, Communication and Organization, PO Box 217, 7500 AE Enschede, the Netherlands.

E-mail address: a.j.a.m.vandeursen@utwente.nl (A.J.A.M. van Deursen).
} 
that non-usage results in negative consequences. Meanwhile, the diffusion of the Internet among households has reached high levels in developed countries. As a consequence, the binary classification of access in terms of physical access (having a computer and an Internet connection or not) is considered to have been superseded and replaced by a divide that is supposed to concentrate on a large number of more complex variables and relations. A more refined understanding of the digital divide has developed, and several conceptualizations of how to approach digital divide research exist (DiMaggio and Hargittai, 2001; Kling, 2000; Mossberger et al., 2003; Van Dijk, 2005; Warschauer, 2003). One of the most important factors in these conceptualizations is the differential possession of digital skills. Changes in society demand new skills, especially those related to the Internet as one of the most important means of communication in contemporary society.

Policy makers and new media developers often seem to believe that, with the exception of some seniors, now everybody has access to and can use the Internet. The general public opinion seems to be that Internet skills are not equally distributed in society, but that with the passing away of the oldest age groups, the problem of a lack of Internet skills will solve itself. Society seems to contribute to the view that older people are awkward users of technology. Take, for example, commercials in which seniors are presented as clumsy when using new communication technologies. However, only few measurements and scientific investigations of the actual skill level possessed by populations at large have been conducted. These measurements often focus on basic use of the Internet (e.g., locating the address bar or conducting a search operation). Other studies address one specific aspect of Internet skills. Examples of such skills are navigation (Ford and Chen, 2000), orientation in an hypermedia environment, or getting lost (Ahuja and Webster, 2001; Otter and Johnson, 2000), selecting search results (Aula and Nordhausen, 2006; Birru et al., 2004; Hölscher and Strube, 2000; Pan et al., 2007), defining search queries (Birru et al., 2004; Lucas and Topi, 2002; Spink et al., 2001), and evaluating information (Morahan-Martin, 2004). These studies are typically conducted in the fields of library research, computer science, and educational science, and they help us understand the level of certain skills among people in specific settings. Due to the specific research scope, however, demographic correlates are rarely considered.

As will be further explained in the next section, the unique contribution of this article is the use of an Internet skills definition that accounts for medium- and content-related skills. As will become clear, this distinction is important and provides new way of thinking about Internet skills. Besides applying an in-depth Internet skills definition, measurements are conducted in observational studies instead of surveys that use questions in which respondents are asked for an estimation of their own skills. Observational studies in which actual performances are measured are more valid than using survey instruments (Hargittai, 2005; Merritt et al., 2005; Talja, 2005; Van Deursen and Van Dijk, 2010). In total, three studies are conducted in which a diverse group of Internet users is subjected to actual performance tests. Besides age, other variables considered are gender, education, Internet experience, and amount of Internet use. These explanatory variables have their own unique relation with the two types of Internet skills and appear to be the most important variables to account for when measuring the proposed range of Internet skills (Van Deursen and Van Dijk, in press). The main questions considered are:

Research Question 1: Which of the following factors contribute to the level of Internet skills: Gender, age, educational attainment, Internet experience, and amount of time spent on the Internet?

Research Question 2: What is the relative contribution of each of these factors? 


\section{Theoretical background}

\subsection{Internet skills}

The concept of Internet skills is just one of many concepts that resulted from the rapid diffusion of digital technologies into society. Both Bawden (2001) and Virkus (2003) concluded that, in most cases, the exact nature of these concepts is not adequately defined. Often, authors seem to believe that the definition of a term used is self-explanatory. The development of assessments has been hampered particularly by the lack of consensus on what constitutes measurable dimensions (Ba et al., 2002). One reason to apply the term 'Internet skills' is the association with references applied in digital divide research, where the term 'digital skills' is commonly used (e.g., De Haan, 2004; Fuchs and Horak, 2008; Kvasny, 2006; Mason and Hacker, 2003; Van Dijk, 2005; Van Dijk and Hacker, 2003). Internet skills can be considered a specification; others are, for example, the skills to use mobile telephones or computers. To encourage research to focus in-depth on Internet skills measurements and to support the achievements of digital divide research, Van Deursen and Van Dijk $(2009,2010)$ elaborated four types of Internet skills from an extensive literature overview. Their definition distinguishes between medium- and content-related Internet skills. The first type of medium-related Internet skills are the operational Internet skills, derived from concepts such as instrumental skills (Steyaert, 2002), technical competence (Mossberger et al., 2003), technological literacy (Carvin, 2000), and technical proficiency (Søby, 2003). All these concepts indicate a set of basic skills in using Internet technology. The second type of medium-related Internet skills are the formal Internet skills that relate to the hypermedia structure on which the Internet is built. This structure requires the skills of navigating and orientating in an hypermedia environment (Edwards and Hardman, 1989; Kwan, 2001; Park and Kim, 2000). The two types of content-related skills are information and strategic Internet skills. Information Internet skills are derived from studies that adopt a staged approach in explaining the actions via which users try to fulfill their information needs (Marchionini, 1995). Strategic Internet skills are the capacity to use the Internet as a means of reaching particular goals and for the general goal of improving one"s position in society. The definition for strategic skills is based on classical approaches to decision-making (Miller, 2006).

The applied definition is unique in its distinction between medium- and content-related Internet skills. This distinction can also be applied to other (traditional and digital) media. The common denominator of operational skills is that the use of all media requires certain technical abilities to process the signs and symbols concerned and to command the particular hard- and software. All media have particular formal structures that users should become familiar with too. Subsequently, all media offer particular content that enables searching, selecting, processing, and evaluating information. Finally, all media can be approached with strategic skills to use them as a means to reach a particular benefit or goal. The definition for the four skills when applied to the Internet are listed in Table 1.

Van Deursen and Van Dijk (2010) stress that the four Internet skills are based on individual abilities, making them include relevant skills necessary for the general population to function well in an increasingly digital environment. By both accounting for technical aspects related to the use of the Internet and substantive aspects related to the content provided by the Internet, Van Deursen and Van Dijk avoid a technologically deterministic viewpoint. Their definition illustrates that the provision of operational and formal skills alone is not sufficient when using the Internet. Furthermore, Van Deursen and Van Dijk claim that their definition contains gradients of difficulty and that the four skills have a sequential and conditional nature. Content-related skills 
Table 1

Four types of Internet skills (Van Deursen and Van Dijk, 2009, 2010).

Medium-related Internet skills

Operational Internet skills

Operating an Internet browser:

- Opening websites by entering the URL in the browser's location bar.

- Navigating forward and backward between pages using the browser buttons.

- Saving files on the hard disk.

- Opening various common file formats (e.g., PDF).

- Bookmarking websites.

Operating Internet-based search engines:

- Entering keywords in the proper field.

- Executing the search operation.

- Opening search results in the search result lists.

Operating Internet-based forms:

- Using the different types of fields and buttons.

- Submitting a form.

Formal Internet skills Navigating on the Internet by doing the following:

- Using hyperlinks embedded in different formats such as texts, images, or menu's.

Maintaining a sense of location while navigating on the Internet, meaning:

- Not becoming disoriented when navigating within a website.

- Not becoming disoriented when navigating between websites.

- Not becoming disoriented when opening and browsing through search results.

Content-related Internet skills

Information Internet skills Locating required information, by:

- Choosing a website or a search system to seek information.

- Defining search options or queries.

- Selecting information (on websites or in search results).

- Evaluating information sources.

Strategic Internet skills

Taking advantage of the Internet by doing the following:

- Developing an orientation toward a particular goal.

- Taking the right action to reach this goal.

- Making the right decision to reach this goal.

- Gaining the benefits resulting from this goal.

somehow depend on the medium-related skills because the absence of medium-related skills means that one will not even come to perform the content-related skills. The Internet, for example, makes information-seeking more difficult because it assumes a number of new operational and formal skills to begin with, thereby raising an extra barrier in comparison with the more traditional media skills such as reading and writing. We therefore expect there to be a significant influence of medium-related Internet skills on content-related Internet skills. This leads to the first hypothesis:

H1. The level of medium-related Internet skills has a positive influence on the level of contentrelated Internet skills.

\subsection{Explanatory variables for the level of Internet skills}

The distinction between medium- and content-related skills is further discussed in this section, where the considered explanatory variables for the level of Internet skills are introduced. The first variable is gender, which is often discussed in the digital divide debate. Most of these discussions concern gender differences in physical Internet access or in types of Internet use. Here it is pointed out that in comparison to men, women use the Internet less often, spend less time online, and they less often use high-speed entry (Fallows, 2005; Horrigan, 2008; Ono and Zavodny, 
2003; Wasserman and Richmond-Abbott, 2005). Therefore, women have less opportunity to familiarize themselves with the medium (Lally, 2002) and have less knowledge about the Internet. The result is that men have a better use of the Internet than women (Goulding, 2003). Similarly, Wasserman and Richmond-Abbott (2005) found the level of Internet use to be related to web-knowledge, which was higher among men than among women. Most of these conclusions are based on survey measures of Internet knowledge of skills. Actual performance tests conducted by Hargittai and Shafer (2006) indicate that men and women do not differ much in their skills to search for information online (content-related information Internet skills). This might be explained by the fact that educational differences between men and women have declined in developed countries. This leads to the following hypotheses:

H2. Men have better medium-related Internet skills than women.

H3. Men and women do not differ in the level of content-related Internet skills.

As discussed in the first section, the general opinion is that younger generations are especially considered skilled users of the Internet. The idea behind this opinion is that younger generations have had exposure to the Internet throughout their entire life. Seniors have never had the opportunity to acquaint themselves with the Internet at school and therefore lag behind in their ownership and use of the Internet (De Haan et al., 2002). Furthermore, seniors have more trouble learning Internet skills due to decreased working memory and reaction times (Boyd and Bee, 2009). Although it is rarely tested whether the younger generations indeed have higher levels of Internet skills (Bennett et al., 2008), there is some empirical evidence. Cho et al. (2003), for example, found that both young and upper-class users were most effective in obtaining what they sought online. The performance tests conducted by Hargittai (2002) led to the conclusion that age is negatively associated with one's level of Internet skill. However, of those studies that point out differences in Internet skills between young and senior Internet users, none of them accounted for differences in medium- and content-related Internet skills. Regarding the first, we indeed expect age to have a negative influence. This in turn might also influence the level of content-related Internet skills because of the expected conditional nature of the medium- and content-related Internet skills. However, it remains unknown what the direct effect of age is on the level of content-related Internet skills. Some studies found that, although students use the Internet at a relatively young age, they still lack some of the content-related Internet skills such as reflection regarding search results (e.g., Pritchard and Cartwright, 2004). This leads to the following hypotheses:

H4. Age has a negative influence on the level of medium-related Internet skills.

H5. Age has a no influence on the level of content-related Internet skills.

Besides gender and age, it is also important to consider educational level of attainment in Internet skills measurement. In fact, this variable is the most consistent global predictor for the use of information communication technologies such as computers and the Internet. In general, the higher educated part of the population is characterized by high levels of computer ownership, the availability of Internet access at home, high levels of broadband connectivity, and by spending a more than average time online (Buente and Robbin, 2008; DiMaggio et al., 2004). Katz and Rice (2002) argue that lower educated groups are unable to apply the content provided by the Internet to their functional needs. Goldin and Katz (2008) furthermore argue that the more highly educated are able to keep up with technological advancements and therefore increase their lead over people who are not able to keep up. This leads to the following hypotheses: 
H6. Level of educational attainment has a positive influence on the level of medium-related skills.

H7. Level of educational attainment has a positive influence on the level of content-related skills.

Other variables that should be accounted for when measuring Internet skills are amount of Internet use and Internet experience. According to Hargittai (2002), people who spend more time online-whether at work or any other location-acquire more knowledge about the Internet and thus have better online skills. In general, for both computers and the Internet, the length of previous experience and the amount of current usage are associated with greater technological expertise (Schumacher and Morahan-Martin, 2001). People who have been Internet users for a longer period of time are expected to be better at finding information online because they have more experience to draw on (Hargittai, 2002). With experience, the Internet assumes an increasingly important role in Internet users' lives in terms of how they obtain information and it can even become an integral part of their daily lives (Renahy et al., 2008). Searching on the Internet would thus become a habit or even an automatic reflex when searching for any information in general (Renahy et al., 2008).

H8. Internet experience has a positive influence on the level of medium-related Internet skills.

H9. Internet experience has a positive influence on the level of content-related Internet skills.

H10. The number of hours spent online has a positive influence on the level of medium-related skills.

H11. The number of hours spent online has a positive influence on the level of content-related skills.

\subsection{Core model}

The hypotheses from the former section together lead to the model presented in Fig. 1. This model shows the expected relations between the explanatory independent variables and the dependent variables of medium- and content-related Internet skills.

\section{Method}

\subsection{Method of data collection}

Three performance tests are conducted to test the model presented in Fig. 1. The first test took place between September and December 2007, the second between September and December 2008, and the third between October 2009 and April 2010. All three Internet skills performance tests were conducted in a university office. Shortcomings of using this particular location include the negative influence on response rates, the use of a location with which people are not familiar, and the use of a computer that is configured differently from the machine people usually use. This may influence the results, as certain settings (e.g., the default home page or keyboard layout) are not equivalent to their own. However, advantages include the fact that this approach controls for quality of the Internet connection and of hardware/software and that the setting is equally different and new for all.

After arriving at the laboratory, subjects were given verbal instructions about the procedure of the study. Prior to the test, a 10-minute questionnaire was administered to gather personal 


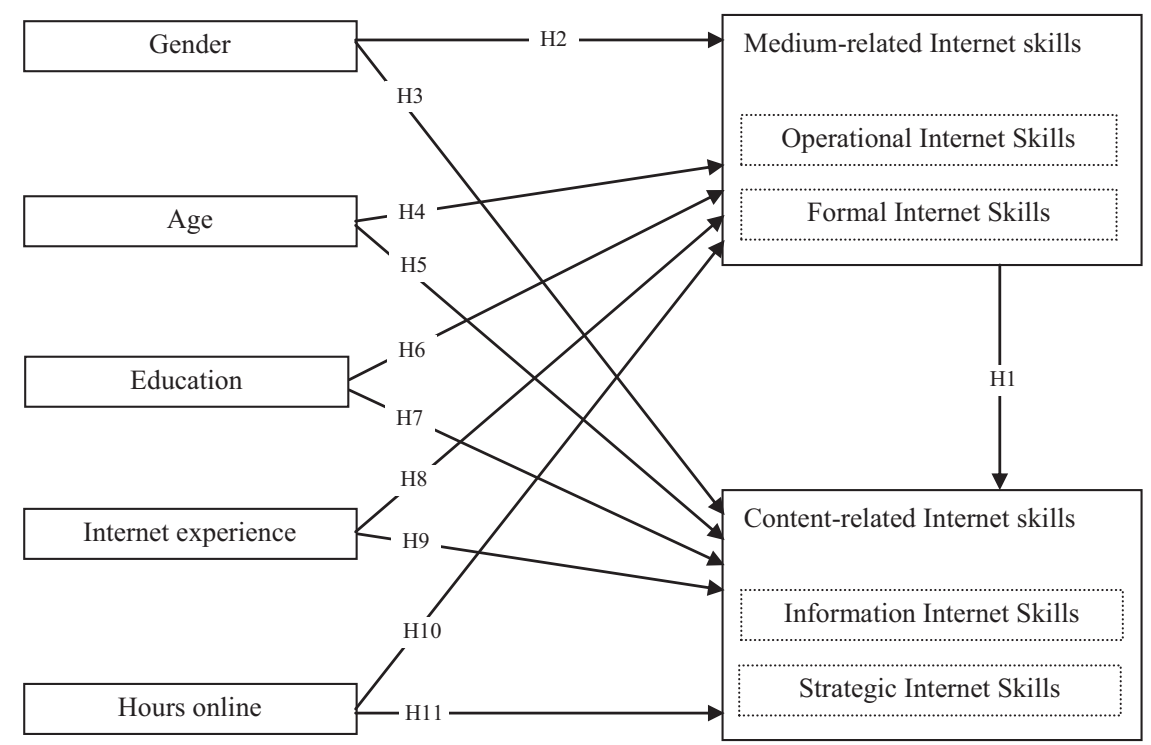

Fig. 1. Model and hypotheses.

data. After the subjects completed the questionnaire, they were given a sequence of nine assignments, one at a time. Subjects themselves decided when they were finished or wanted to give up on an assignment. No encouragements were given because the pressure to succeed is already higher in a laboratory setting than at home. After a specific maximum amount of time had passed (determined from the pilot-tests), the test-leader gently asked the subjects to move on to the next assignment. If the correct answer was not found, the task was rated as not completed. The test leader refrained from influencing the subjects' strategies and directly measured whether the task was completed successfully (which is the case when the correct answer was found).

During the assignment completion, subjects used a keyboard, a mouse, and a 17-inch monitor. These were connected to a laptop from which the test-leader could watch the subjects' actions. The laptop had access to a high-speed university network for Internet use and was programmed with the most popular Internet browsers (Microsoft Internet Explorer, Mozilla Firefox, and Google Chrome). This allowed subjects to replicate their regular Internet use. No default page was set on the browsers, and all the assignments started with a blank page. To ensure that subjects were not influenced by previous user's actions, the browser was reset after each session by removing temporary files, cookies, and favorites. In addition, downloaded files, history, form contents, and passwords were removed, and the laptop was rebooted.

\subsection{Sample}

In line with the performance test conducted by Hargittai (2002), we made the condition of invitation that the subject used the Internet at least once every month for more than just e-mail. This condition excluded approximately $20 \%$ of the Dutch population, but ensured that lowfrequency users who were nonetheless familiar with the Internet were included. The subjects were not informed about the exact intention of the studies. They were told the study would cover 
Table 2

Number of subjects over gender, education, and age.

\begin{tabular}{lllr}
\hline & $\begin{array}{l}\text { Study } 1 \\
n(\%)\end{array}$ & $\begin{array}{l}\text { Study } 2 \\
n(\%)\end{array}$ & $\begin{array}{l}\text { Study } 3 \\
n(\%)\end{array}$ \\
\hline $\begin{array}{l}\text { Gender } \\
\text { Male }\end{array}$ & $51(47 \%)$ & $57(52 \%)$ & $45(51 \%)$ \\
Female & $58(53 \%)$ & $52(48 \%)$ & $43(49 \%)$ \\
Education & $32(29 \%)$ & $34(31 \%)$ & $25(28 \%)$ \\
Low & $37(34 \%)$ & $34(31 \%)$ & $32(36 \%)$ \\
Middle & $40(37 \%)$ & $41(38 \%)$ & $31(35 \%)$ \\
High & $25(23 \%)$ & $27(25 \%)$ & $24(27 \%)$ \\
Age & $27(25 \%)$ & $23(21 \%)$ & $18(21 \%)$ \\
$18-29$ & $27(25 \%)$ & $28(26 \%)$ & $23(26 \%)$ \\
$30-39$ & $30(27 \%)$ & $30(28 \%)$ & $23(26 \%)$ \\
$40-54$ & & & \\
$55-80$ & & & \\
\hline
\end{tabular}

general Internet use. The invitation policy put people who feared a test at ease. Only adult Dutchspeaking users were included.

To be able to generalize from the findings, subjects were recruited by applying a stratified random sampling method. First, a sample was randomly selected from a telephone book of Twente (an eastern region in the Netherlands). Subsequently, people in this sample were contacted and asked for their participation. If willing to participate, the respondent was screened for gender, age, and education. This was repeated until equal subsamples of gender, age (equal number of subjects in the categories of age 18-29, 30-39, 40-54, and 55-80), and educational level of attainment (equal number of subjects in the categories low, middle, and high) were reached. When respondents indicated they were willing to participate, their contact mailing address and e-mail address were recorded, and a time for the research session was scheduled. Respondents received a confirmation/ follow-up letter in the mail with directions to the research site. The day before the study, respondents were reminded of the session by phone. After the session (which took approximately one and a half hours), subjects were rewarded with 25 Euro for their participation.

Both in the first and second study, 109 subjects participated (response rates to the invitation were $28 \%$ and $32 \%$, respectively). In the third study, 88 subjects participated (response rate was $19 \%$ ). Table 2 contains the number of subjects in the three studies and their breakdown in terms of gender, age, and educational attainment. The average years of Internet experience was 8.1 ( standard deviation $=3.0), 8.3(S D=3.2)$, and $9.3(S D=4.3)$, and the average amount of Internet use was 9.7 hours a week $(S D=9.7), 9.5$ hours a week $(S D=10.2)$, and 12.3 hours a week $(S D=13.7)$ in studies 1,2 , and 3, respectively. The average age of the subjects was 43.4 $(S D=15.5), 43.2(S D=17.1)$, and $42.5(S D=17.5)$, respectively. Overall, the people who participated in the three studies represent a diverse group of Internet users.

\subsection{Assignments}

Two assignments (consisting of eight sub-tasks) were used to measure operational Internet skills, two (consisting of four sub-tasks) for measuring formal Internet skills, three for measuring information Internet skills, and two for measuring strategic Internet skills. The assignments applied situations that are closely linked to the types of real-life questions that people face, as the presence of a real information need makes observation a means for gaining valuable insight into 
users' natural behavior (Shneiderman et al., 1997). All assignments are fact-based and have one specific correct action or answer. Open-ended tasks are avoided because of the ambiguity of interpretation of the many potential answers. Before the three performance tests were conducted, 12 subjects were recruited to participate in a pilot-test in which the assignments were tested for comprehensibility and applicability. A conscious effort was made to include seniors and lesseducated individuals. After the pilot-tests, some formulations in the task descriptions were adjusted.

In the first study, assignments were related to government information and services. Some of the assignments were derived from the 10 most used search queries in the general Dutch government's Internet portal. The second study used a more popular context, in which general, leisure-related assignments geared toward everyday experiences of Internet users had to be completed. Assignments in the third study were all health-related and accessible to the general user population. The full list of the assignments charged to the subjects and the maximum amount of time for every assignment are listed in Appendix A.

The total outcome for every skill is measured as the number of tasks solved successfully. The level of medium-related Internet skills is determined by the total number of successfully completed operational and formal Internet skills. The level of the content-related Internet skills is determined by the total number of successfully completed information and strategic Internet skills.

\section{Results}

\subsection{Overview of assignment completion}

Table 3 provides an overview of the average completion rate of the Internet skills assignments over the three studies. It appears that the Dutch population on average has a fairly high level of operational and formal Internet skills, but that the levels of information and especially strategic Internet skills attained are much lower. These particular results and their implications are discussed in Van Deursen and Van Dijk (in press). Here, we are mainly interested in testing the model presented in Fig. 1.

\subsection{Analyses}

To test the conceptual model presented in Fig. 1, structural equation modeling using Amos 17.0 (Arbuckle, 2010) was applied. Structural equation modeling is a statistical methodology that takes a confirmatory (i.e., hypothesis-testing) approach to the analysis of a structural theory bearing on some phenomenon (Byrne, 2001). Typically, this theory represents causal processes that generate observations on multiple variables (Bentler, 1989). Synonyms for structural

Table 3

Overview of average successful task completion in all three studies.

\begin{tabular}{lll}
\hline & \multicolumn{1}{l}{ Task completion } \\
\cline { 2 - 3 } & $M(S D)$ & 75 \\
\hline Operational Internet skills tasks (8) & $6.0(1.8)$ & 75 \\
Formal Internet skills tasks (4) & $3.0(1.0)$ & 53 \\
Information Internet skills tasks (3) & $1.6(0.9)$ & 30 \\
Strategic Internet skills tasks (2) & $0.6(0.7)$ & \\
\hline
\end{tabular}

Note: $M=$ mean; $S D=$ standard deviation. 
equation modeling are covariance structure analysis, covariance structure modeling, and analysis of covariance structures. According to Byrne, the term structural equation modeling conveys two important aspects of the procedure: (1) that the causal processes under study are represented by a series of structural (i.e., regression) equations, and (2) that these structural relations can be modeled pictorially to enable a clearer conceptualization of the theory under study. The hypothesized model can then be tested statistically in a simultaneous analysis of the entire system of variables to determine the extent to which it is consistent with the data. Byrne (2001) poses that if the goodness of fit is adequate, the model argues for the plausibility of postulated relations among variables; if it is inadequate, the tenability of such relations is rejected.

To test the hypotheses, the number of tasks completed successfully for all four types of Internet skills are standardized in all performance tests. Then, the results of the three performance tests are merged together creating a larger sample necessary for applying structural equation modeling. Merging the results is allowed because the measurement of Internet skills was similar (except for the specific content); the exact same structure for all tasks was used. Furthermore, all tests applied a similar quota sample over gender, age, and education. The three studies together created a sample of 306 subjects that actually performed assignments on the Internet; this was the most valid testing method. Hoelter's critical $N$ is used to judge if the eventual sample size is adequate for applying structural equation modeling. The model as presented in Fig. 2 resulted in a Hoelter's $N$ of 333 (at the .05 levels of significance) and 415 (at the .01 levels of significance), sufficient since sample size is adequate if Hoelter's $N>200$.

The correlation matrix of the variables is shown in Table 4 . The correlations between gender and the four Internet skills are not significant. From these results, gender can be excluded from the path analysis (inclusion does not lead to a fitted model).

To test the first hypothesis (that medium-related Internet skills have a positive influence on the level of content-related Internet skills), two path analyses were conducted. One path analysis involved a direct path from medium-related skills to content-related skills, while the other path analysis did not include a direct path. The results obtained by testing the validity of a causal structure with a direct path from medium-related skills to content-related skills showed a good fit, $\chi^{2}(11)=19.01, \quad \chi^{2} / \mathrm{df}=1.73, \quad$ SRMR $=.032, \quad$ TLI $=.972, \quad$ RMSEA $=.049 \quad(90 \%$ confidence interval $[\mathrm{CI}]: .000, .085), \mathrm{AIC}=69.013, \mathrm{ECVI}=.226$ (CI: .200, .279). The results obtained by testing the validity of a causal structure without a direct path from medium-related skills to contentrelated skills showed a poor fit, $\chi^{2}(12)=44.38, \chi^{2} / \mathrm{df}=3.70, \mathrm{SRMR}=.055, \mathrm{TLI}=.895$, RMSEA $=.094(90 \%$ confidence interval $[\mathrm{CI}]: .065, .124), \mathrm{AIC}=92.381, \mathrm{ECVI}=.303(\mathrm{CI}$ : $.248, .383)$.

Table 4

Correlation matrix.

\begin{tabular}{lllllllrrr}
\hline & 1 & 2 & 3 & 4 & 5 & 6 & 7 & 8 & 9 \\
\hline 1. Gender & - & -.03 & -.04 & -.03 & -.16 & -.10 & -.02 & -.06 & -.02 \\
2. Age & - & - & -.09 & -.15 & -.40 & -.52 & -.43 & -.04 & -.07 \\
3. Education & - & - & - & .27 & .11 & .28 & .33 & .32 & .46 \\
4. Internet experience (yrs) & - & - & - & - & .18 & .17 & .24 & .16 & .19 \\
5. Hours online & - & - & - & - & - & .31 & .16 & .11 & .07 \\
6. Operational skills & - & - & - & - & - & - & .67 & .34 \\
7. Formal skills & - & - & - & - & - & - & - & .34 \\
8. Information skills & - & - & - & - & - & - & - & - & .30 \\
9. Strategic skills & - & - & - & - & - & - & - & - & - \\
\hline
\end{tabular}

Note: Significant at $p<.05$; non-significant correlations are in italics. 


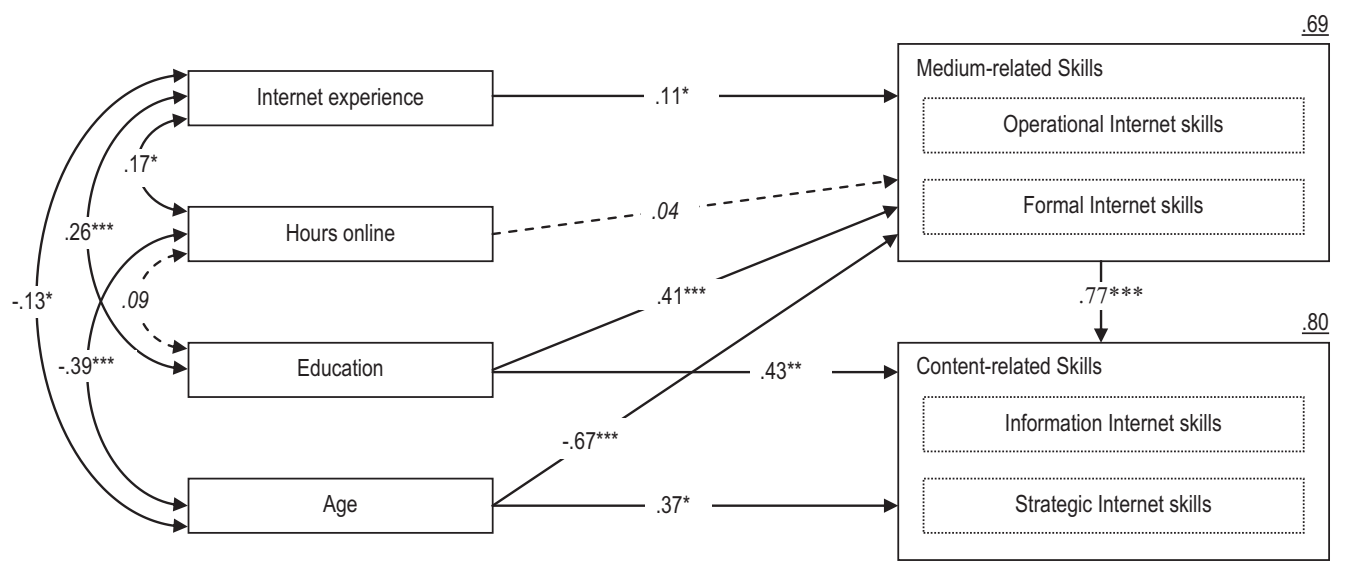

Fig. 2. Standardized path coefficients of the model. Note: ${ }^{*} p<.05,{ }^{*} p<.01,{ }^{*} * *<.001$. The dotted line is a nonsignificant path (non-significant factor loadings in italics). Squared multiple correlations are underlined.

To test hypotheses H8-H11, an additional path analysis was conducted without direct paths from Internet experience and hours online to content-related skills. The results obtained by testing the validity of a causal structure without the direct paths from Internet experience and hours online to content-related skills showed an improved fit, $\chi^{2}(12)=19.31, \chi^{2} / \mathrm{df}=1.61$, SRMR $=.033, \quad \mathrm{TLI}=.976, \quad \mathrm{RMSEA}=.045(90 \%$ confidence interval $[\mathrm{CI}]: .000, .080)$, $\mathrm{AIC}=67.311, \mathrm{ECVI}=.221(\mathrm{CI}: .197, .274)$. The path model with standardized path coefficients is featured in Fig. 2. This figure summarizes the factor loading $(\beta)$ of the variables and the squared multiple correlation $\left(R^{2}\right)$ for the medium- and content-related Internet skills.

The standardized path coefficients show a significant direct effect of Internet experience, education, and age on medium-related skills. The direct effect of hours spent online weekly on medium-related skills is not significant. Fig. 2 also shows significant direct effects of education, age, and medium-related skills on content-related skills. Squared multiple correlations provide information about the variance accounted for by the complete set of variables, and they show that medium-related skills accounted for $69 \%$, and content-related skills accounted for $80 \%$.

\subsection{Overview of the hypotheses}

Hypothesis H1 - that medium-related Internet skills positively affect the level of contentrelated skills - is accepted. The correlation between these skills is high and significant, indicating that a higher level of medium-related skills contributes to higher levels of content-related skills.

Hypotheses $\mathrm{H} 2$ - that men have better medium-related Internet skills than women-is rejected. Hypothesis $\mathrm{H} 3$ - that men and women do not differ in the level of content-related Internet skills-is accepted. Since there were no significant relations between gender and the four Internet skills, there is no influence of gender on any of these skills.

Hypothesis $\mathrm{H} 4$ - that age negatively affects the level of medium-related skills-is accepted. The elderly perform more poorly than the younger generations with regard to medium-related skills, as was expected. Hypothesis H5-that age has no influence on the level of content-related Internet skills - is rejected. There is a direct, positive, significant effect of age on content-related skills, meaning that the older generations perform better than the younger with regard to these 
skills. However, the final results of the performance tests measuring both medium- and content-related skills are still negative. The direct effect of age on content-related Internet skills is mediated by the indirect effect of age on medium-related skills. When the path from age to medium-related Internet skills $(\beta=-.67)$ is multiplied by the path from mediumrelated skills to content-related skills $(\beta=.77)$ and summed with the direct path from age to content-related Internet skills $(\beta=.37)$, the result is a $\beta$ of -.15 . This indicates that mediumrelated skills have a major influence on the performance of content-related-skills, so that the older generations still score slightly lower on performance tests than young people with regard to these skills.

Hypotheses H6 - that education positively affects the level of medium-related skills-and H7-that education positively affects the level of content related skills—are both accepted. The level of educational attainment affects both medium- and content-related Internet skills. The total effect of education on content-related skills $(\beta=.75)$ results from the direct effect of education on content-related skills added by the indirect effect of education on medium-related skills.

Although hypothesis H8- that Internet experience has a positive influence on the level of medium-related Internet skills-is accepted, hypothesis H9-that Internet experience has a positive influence on the level of content-related Internet skills-is not. The number of years of Internet use only seems to contribute to the level of medium-related Internet skills. In addition, both hypothesis $\mathrm{H} 10$ - that the number of hours spent online weekly has a positive influence on the level of medium-related skills - and hypothesis H11 - that the number of hours spent online weekly has a positive influence on the level of content-related skills-are rejected.

\section{Discussion}

\subsection{Main findings}

From the measurement model presented in Fig. 2, we are able to address both our research questions. Age appears to be a significant contributor to medium-related skills, being operational and formal Internet skills. Younger people perform better on these skills than older people do. However, the results regarding content-related skills prove different. In fact, age positively contributes to the level of content-related skills, meaning that older people perform better than the younger ones on the condition that they have an adequate level of medium-related skills. Due to the lack of medium-related Internet skills, however, older people are seriously limited in their content-related skills. The results indicate that the popular and unpleasant assumption that the skill problem will solve itself with the loss of the oldest age groups is false. This assumption should be carefully reconsidered and seems to be primarily based on the level of operational and formal Internet skills. Unfortunately, this assumption is further strengthened by older people themselves. People who have little confidence in their ability to use the Internet, who are dissatisfied with their Internet skills or who are uncomfortable using the Internet may be said to have weak self-efficacy beliefs (Eastin and LaRose, 2000). Unfortunately, those with low levels of self-efficacy are less likely to adopt and use the Internet in the future than those with high degrees of self-efficacy (Eastin and LaRose, 2000).

Regarding the effects of age, we would like to emphasize that these results account for the current era and current generations. We do not know whether the same differences will persist in the future. Although operational and formal skill-related problems are easiest to account for, they might persist since technology changes and with these changes new specific operational and formal skill-related problems will come into existence. 
The most important factor-influencing all types of Internet skills-is the level of educational attainment. Research within the digital divide discourse is often highly marked by differences in educational attainment, especially concerning Internet access. Although low general literacy levels are often related to digital inequality, regarding Internet skills another assumption is very common. It is often argued that people learn Internet skills more in practice, by trial and error, than in formal educational settings (e.g., De Haan et al., 2002; Van Dijk, 2005). From the results it is possible to conclude that this mainly goes for operational and formal Internet skills, but not for information and strategic skills.

It is noteworthy that the level of Internet skills has such a weak relation with years of Internet experience and with the number of hours spent online weekly. Internet experience only contributes to medium-related skills. This might be explained by the fact that people often keep repeating similar mistakes when using computers. Computer users tend to rely on acquired skills, even when they are aware that they could learn more efficient procedures for achieving the same results (Cahoon, 1998). This might also account for Internet users. People learn by trial and error, but when they more or less achieve the goals they had in mind, people will persist in making the same mistakes online. This will certainly be the case when there is no one around to point out mistakes.

Content-related skills do not grow at all with years of Internet experience and number of hours spent online weekly. This further enervates the assumption that with the passing away of seniors the Internet skill problem will solve itself. Especially regarding information and strategic Internet skills, it is educational level of attainment that is most relevant. These skills strongly relate to the possession of general intellectual skills that do not gain from long or heavy Internet use.

Gender did not reveal any differences. Because education plays such a significant role when considering Internet skills, the lack of significant results for gender can primarily be explained by the fact that, in the Netherlands, to a large extent gender differences within education have disappeared.

\subsection{Limitations}

The studies discussed provide a comprehensive overview of the Internet skill levels of different segments of the Dutch population and reveal that basic assumptions concerning Internet skills should be carefully reconsidered. The measurement of these skills, however, was limited to informationrelated activities. Although these activities remain the most widely used (Witte and Mannon, 2009), the communication capacities of the Internet have gained considerable attention over the last few years. Communication Internet skills were not measured because this would have made the performance tests, which already required 1.5 hours of the subjects' time, an unrealistic effort. In addition, content creation and sharing have also been ignored. We suggest that information and strategic skills are crucial for these activities even more than for information retrieval. Active participation and user-generated content require a high level of Internet skills. Both limitations are something that future research should consider in developing operational definitions and measurements of skills related to communication, interaction and peer-to-peer networking on the Internet.

We do not know whether the observed differences between the explanatory variables and the two types of Internet skills also account for the more traditional media. Further research should answer this question by adding comparable skills performance tests of the use of other media than the Internet. A comparison of the results of all these tests could show us whether the use of the Internet makes a difference and whether Internet use aids us in achieving better information and 
better test results or if it introduces another barrier because many people do not master the special skills required for appropriate use of the Internet. Our assumption would be that, while computers and the Internet make things easier because they enable systematic information retrieval from innumerable sources simultaneously, finding information in a traditional library might be more difficult for inexperienced information seekers than finding the same information on the Internet using a 'simple' search engine. On the other hand, computers and the Internet make the content-related Internet skills more difficult because they assume a number of new medium-related skills to start with. This introduces yet another barrier in addition to the skills of reading and writing. Furthermore, computers and the Internet require particular contentrelated skills that are somewhat different from those required for the use of traditional media. Otherwise, one will make wrong selections based on information sources, make wrong decisions trying to achieve particular aims, or drown in the wide ocean of information provided by the digital media. All four skills taken together probably make the gap between people with different educational, and age backgrounds larger for the new media than for more traditional outlets.

\section{Appendix A}

\section{List of Assignments in Study 1}

\section{Operational skill assignments}

Assignment 1. (max. 12 minutes)

- 1.1: Go to the website of the Dutch Tax Administration (www.belastingdienst.nl).

- 1.2: Click on the link 'Download and order' in the menu on the right.

- Click on the subject 'Marriage'.

- Click on the link 'When you are getting married'.

- 1.3: Open the brochure 'When you are getting married'.

- Save the brochure in the folder 'Marriage' on the desktop.

- 1.4: Use the back-button to go back to 'Download and order'.

o Click on the link 'Declaration 2006'.

- Click on 'Declaration software 2006 (Windows)'.

- 1.5: Save the file 'Electronic declaration IB 2006 for Windows' on the desktop.

- 1.6: Go back to the homepage of the Tax Administration.

- Add the homepage to the favourites (or bookmarker).

- 1.7: Use the search engine using the keyword 'save-as-you-earn deduction'.

- Open the third search result of the search assignment.

\section{Assignment 2. (max. 8 minutes)}

- 2.1: Go to the Child care allowance website: www.toeslagen.nl/reken/kinderopvangtoeslag/.

- Complete the fields using the information given.

Formal skill assignments

Assignment 3. (max. 10 minutes)

- 3.1: Go to the website of the Central Office of Information (www.postbus51.nl).

- Follow the options Accommodation/Rent/Rental price/Rent Subsidy.

o Choose the option: 'What is rent subsidy and how do I apply for it?'. 
- 3.2: Click on the link 'Applying for rent subsidy'.

- Go to the homepage of the Allowance website in the new window.

$\circ$ Go back to the homepage of Postbus51 in the old window.

- 3.3: Perform a search on the Postbus51 website with keyword 'rental price'.

- Open the first search result.

- Open the second search result.

\section{Assignment 4. (max. 10 minutes)}

- 4.1: Imagine that you just moved to Nijmegen. You would like to look up the office addresses of the IB-Groep, UWV and CWI.

\section{Information skill assignments}

\section{Assignment 5. Parking (max. 12 minutes)}

- Imagine that you just moved to Rotterdam. Because it is hard to find a parking spot, you decide to buy a subscription. Find out how much a subscription to the car park named 'Spaanse Kade' costs. Use the homepage of Rotterdam (www.rotterdam.nl).

\section{Assignment 6. Theft (max. 12 minutes)}

- Imagine that your passport is stolen. Use a search engine to find out what type of document you need to apply for a new passport after the old one is stolen.

\section{Assignment 7. Salary (max. 12 minutes)}

- Imagine that you are 25 years old. In between September 1st and December 30th you had a fulltime job in a factory. Your wage was 1275 Euro gross every month. Use a search engine to find out whether you were entitled to a higher salary during this period. (Yes, because the salary was lower than _ Euro./No, because the salary was higher than _ Euro.)

Strategic skill assignments

\section{Assignment 8. Salary (max. 12 minutes)}

- When your employer underpaid you, what financial 'benefit' can you then personally obtain? Sort this out using the Internet.

\section{Assignment 9. Elections (max. 30 minutes)}

- Image that there are national elections soon. You are in doubt whether to vote for the PvdA, the CDA or the VVD. You have the following opinions:

$\circ$ In favour of using nuclear energy;

○ In favour of a high child care allowance;

$\circ$ Against having two nationalities.

- Using the Internet, find out which of these three political parties have your first, second and third preference.

\section{List of Assignments in Study 2}

Operational skill assignments

Assignment 1. (max. 6 minutes)

- 1.1: Go to the website of the CBR (www.cbr.nl).

- 1.2: Click on the link 'Motor' in the menu on the left. 
- Click on the subject 'Motor and scooter'.

- 1.3: Open the brochure 'Motor and scooter'.

o Save the brochure in the folder 'CBR' in My Documents.

- 1.4: Use the back button to go back to homepage of the CBR website.

- 1.5: Add the homepage to the Favourites (or bookmarks).

\section{Assignment 2. (max. 5 minutes)}

- 2.1: Go to the website of Marktplaats (www.marktplaats.nl) and click on the link 'Uitgebreid zoeken'.

○ Complete the fields using the information given.

- 2.2: Conduct the search en open the third search result.

- 2.3: Save the logo of Markplaats in the upper left corner on the desktop of the computer.

\section{Formal skill assignments}

\section{Assignment 3. (max. 8 minutes minutes)}

- 3.1: Go to the website of the ANWB (www.anwb.nl).

- Follow the options Car/Sell/Selling.

- Choose the option: 'Selling my car via AutoTrader'.

- 3.2:

- Go to the homepage of the Autotrader website in the new window.

$\circ$ Go to the homepage of the ANWB in the old window.

- 3.3: Perform a search on the ANWB website with keyword 'beach'.

o Open the first search result.

$\circ$ Open the second search result.

\section{Assignment 4. (max. 8 minutes)}

- Find the addresses of the following three Museums. Use the museums' website:

$\circ$ Het Mauritshuis (www.mauritshuis.nl/).

$\circ$ Het Museon (www.museon.nl/).

○ Het Letterkundig Museum (www.letterkundigmuseum.nl).

Information skill assignments

\section{Assignment 5. T-mobile (max. 10 minutes)}

- Imagine. . 8 months ago you subscribed to a mobile telephone contract with T-mobile. Now you would like to take advantage of the new T-mobile iPhone offer. Answer the following question, using the T-mobile website (www.t-mobile.nl): Is it possible to subscribe to a Tmobile iPhone contract as a continuation of your current subscription?

\section{Assignment 6. Restaurant (max. 10 minutes)}

- Imagine... You would like to go out for a luxury dinner in Amsterdam. You prefer the restaurant with the most Michelin stars. Answer the following question using a search engine: What restaurant would you go to?

\section{Assignment 7. Go boating (max. 12 minutes)}

- Imagine. . . You bought a rubber boat of 9.84 feet in length. You can reach a maximum speed of $17 \mathrm{mph}$ with this boat. Answer the following question using a search engine: Are you allowed to use this boat in public waters like the Maas? 


\section{Strategic skill assignments}

\section{Assignment 8. Shopping in Amsterdam (max. 15 minutes)}

- Imagine. . . You and your partner take your son out for shopping in Amsterdam. You would like to go by car, but the ride would cost you 4 Euros for every 12.4 miles, not counting 4 hours of parking in the centre of Amsterdam. Because your son has a train pass (which might offer possibilities for you too), you wonder if the train would be cheaper than using the car. Use the Internet to figure this out.

\section{Assignment 9. Travelling (max. 25 minutes)}

- Imagine. . From March the 7th through the13th of next year you are planning a trip to London with your partner. You would like to book two tickets from a nearby airport (in the Netherlands) and a hotel in the centre of London. Find out how much this would cost using the Internet, aiming to identify the cheapest options. Consider flight, hotel and travel expenses to and from the airport in London.

\section{List of Assignments in Study 3}

\section{Operational Internet skills}

\section{Assignment 1 (max. 12 minutes)}

- 1.1: Go the website of the RIVM (www.rivm.nl).

- 1.2: Click on the link 'Infectieziekten' in the menu on the left.

- Click on the subject 'Thema's'.

- Click on the subject 'Hoofdluis'.

- Click on the subject 'Voorlichtingsmateriaal downloaden'.

- 1.3: Open the brochure 'Veelgestelde vragen'.

- Save the brochure in "My Documents".

- 1.4: Use the back button to go back to homepage of the RIVM Website.

- 1.5: Add the homepage to the Favourites (or bookmarks).

\section{Assignment 2 (max. 8 minutes)}

- 2.1: Click on the link 'Uitgebreid zoeken'.

- Complete the fields using the information given.

- 2.2: Execute the search function and open the third search result.

- 2.3: Save the logo of the MinVWS on the desktop of the computer.

\section{Formal Internet skills}

\section{Assignment 3 (max. 10 minutes)}

- 3.1: Go to the website of ZonMW (www.zonmw.nl).

○ Follow the options: Onderwerpen/Jeugd/Zorg.

○ Choose the option: 'RIVM/Jeugdgezondheid'.

- 3.2:

- Go to the homepage of the RIVM website in the new opened window.

$\circ$ Go to the homepage of the RIVM website in the original window.

- 3.3: Perform a search on the ZonMW website with keyword 'infectie'.

o Open the first search result.

$\circ$ Open the fourth search result. 


\section{Assignment 4 (max. 10 minutes)}

- Find the addresses of the following three health organizations. Use the websites of the organization:

$\circ$ ISALA Clinic in Zwolle (www.isala.nl).

- BOSK Organization for the disabled (www.bosk.nl/).

○ GGZ Enschede (www.ggznederland.nl).

\section{Information Internet skills}

\section{Assignment 5 (max. 12 minutes)}

- Imagine... You would like to know more about H1N1 influenza, originally called Swine Flu. Answer the following question, using the website of Dokterdokter (www.dokterdokter.nl): Why is the name Swine flu not correct?

\section{Assignment 6 (max. 12 minutes)}

- Imagine. . . During a hike you are bitten by a tick. A red spot appears that increases. This is a sign you have been infected with Lyme borreliosis. A friend recommends to start with an antiviral (remedy against viral infections) immediately, since Lyme's disease can have very unpleasant consequences when treatment starts too late! Answer the following question using a search engine: Is it a good idea to start an antiviral remedy?

\section{Assignment 7 (max. 12 minutes)}

- Imagine... The last few months, your son has been suffering problems with his back. His back shows a deviation to the left. It looks like one leg is shorter than the other, although this does not appear to be the case. Answer the following question using a search engine: What is the name of the condition your son suffers from?

\section{Strategic Internet skills}

\section{Assignment 8 (max. 12 minutes)}

- Imagine... You have a three year old son. Your mother gives you the advice to give him extra vitamins $\mathrm{A}$ and $\mathrm{D}$. Your mother believes these are necessary for a healthy growth. Answer the following question by using the Internet: Would you give your son both extra vitamins A and D?

\section{Assignment 9 (max. 30 minutes)}

- Imagine... Your mother is 82 years old. Lately, she has been suffering from dementia and impaired hearing. You decided to find a homecare organization in the city of Enschede that has a special caring program for these complaints. You also would like the organization to organize daily activities for seniors. Use the Internet to find a homecare organization in Enschede that meets your demands.

\section{References}

Ahuja, J.S., Webster, J., 2001. Perceived disorientation: an examination of a new measure to assess web design effectiveness. Interacting with Computers 14, 15-29.

Aula, A., Nordhausen, K., 2006. Modeling successful performance in web searching. Journal of the American Society for Information Science and Technology 57, 1678-1693. 
Ba, H., Tally, W., Tsikalas, K., 2002. Investigating children's emerging digital literacies. Journal of Technology, Learning and Assessment 1, 1-48.

Bawden, D., 2001. Information and digital literacies: a review of concepts. Journal of Documentation 57, $218-259$.

Bennett, S., Maton, K., Kervin, L., 2008. The digital natives debate: a critical review of the evidence. British Journal of Educational Technology 39, 775-786.

Bentler, P.M., 1989. Theory and Implication of EQS: A Structural Equations Program. BMDP Statistical Software, Los Angeles.

Birru, M.S., et al., 2004. Internet usage by low-literacy adults seeking health information: an observational analysis. Journal of Medical Internet Research 6, e25.

Boyd, D.A., Bee, H., 2009. Lifespan Development. Pearson, Boston.

Buente, W., Robbin, A., 2008. Trends in Internet information behavior, 2000-2004. Journal of the American Society for Information Science and Technology 59, 1743-1760.

Byrne, B.M., 2001. Structural Equation Modeling with AMOS: Basic Concepts, Applications and Programming. Erlbaum, Mahwah, NJ.

De Haan, J., 2004. A multifaceted dynamic model of the digital divide. IT\&Society 1, 66-88.

Cahoon, B., 1998. Teaching and learning Internet skills. New Directions for Adult and Continuing Education 78, 5-13.

Carvin, A., 2000. More than Just Access: Fitting Literacy and Content into the Digital Divide Equation. Retrieved from http://www.educause.edu/.

Cho, J., Gil de Zúñiga, H., Rojas, H., Shah, D., 2003. Beyond access: the digital divide and Internet uses and gratifications. IT\&Society $1,46-72$.

De Haan, J., Huysmans, F., Steyaert, J., 2002. At Home in a Digital World: Acquiring Digital Skills between Home and School. Social and Cultural Planning Agency, The Hague.

DiMaggio, P., Hargittai, E., 2001. From the “Digital Divide” to 'Digital Inequality": Studying Internet Use as Penetration Increases. Working Paper Series 15: Princeton University Center for Arts and Cultural Policy Studies.

DiMaggio, P., Hargittai, E., Celeste, C., Shafer, S., 2004. From unequal access to differentiated use: a literature review and agenda for research on digital inequality. In: Neckerman, K. (Ed.), Social Inequality. Russell Sage Foundation, New York, pp. 355-400.

Eastin, M.S., LaRose, R., 2000. Internet self-efficacy and the psychology of the digital divide. Journal of ComputerMediated Communication 6 (1).

Edwards, D., Hardman, L., 1989. Lost in hyperspace: cognitive mapping navigation in a hypertext environment. In: McAleese, R. (Ed.), Hypertext: Theory into Practice. Ablex, Norwood, NJ, pp. 90-105.

Fallows, D., 2005. How Men and Women use the Internet. Pew Internet and American Life Project, Washington, DC.

Ford, N., Chen, S.Y., 2000. Individual differences, hypermedia navigation, and learning: an empirical study. Journal of Educational Multimedia and Hypermedia 9, 281-312.

Fuchs, C, Horak, E., 2008. Africa and the digital divide. Telematics and Informatics 252, 99-116.

Goldin, C., Katz, L.F., 2008. The Race between Education and Technology. Belknap, Cambridge, MA.

Goulding, A., 2003. Women and the information society: barriers and participation. IFLA Journal 29, 33-40.

Hargittai, E., 2002. Second-level digital divide: differences in people's online skills. First Monday 7 (4).

Hargittai, E., 2005. Survey measures of web-oriented digital literacy. Social Science Computer Review 23, 371-379.

Hargittai, E., Shafer, S., 2006. Differences in actual and perceived online skills: the role of gender. Social Science Quarterly 87, 432-448.

Hölscher, C., Strube, G., 2000. Web search behavior of Internet experts and newbies. Computer Networks 33, $337-346$.

Horrigan, J.B., 2008. Home Broadband Adoption 2008. Pew Internet \& American Life Project. Retrieved January 2010 from http://www.pewinternet.org/PPF/r/257/report_display.asp.

Katz, J., Rice, R., 2002. Social Consequences of Internet Use: Access, Involvement, and Interaction. MIT Press, Cambridge, MA.

Kling, R., 2000. Learning about information technologies and social change: the contribution of social informatics. The Information Society 16, 217-232.

Kvasny, L., 2006. Cultural (re)production of digital inequality in a US community technology initiative. Information, Communication \& Society 9, 160-181.

Kwan, M.P., 2001. Cyberspatial cognition and individual access to information: the behavioral foundation of cybergeography. Environment and Planning B: Planning and Design 28, 21-37.

Lally, E., 2002. At Home with Computers. Berg, Oxford, UK.

Lucas, W., Topi, H., 2002. Form and function: the impact of query term and operator usage on web search results. Journal of the American Society for Information Science and Technology 53, 95-108.

Marchionini, G., 1995. Information Seeking in Electronic Environments. Cambridge University Press, New York. 
Mason, S.M., Hacker, K.L., 2003. Applying communication theory to digital divide research. IT\&Society 1, 40-55.

Merritt, K., Smith, D., Renzo, J.C.D., 2005. An investigation of self reported computer literacy: is it reliable? Issues in Information Systems 6, 289-295.

Miller, K., 2006. Organizational Communication, Approaches and Processes. Thomson Wadsworth, Belmont, CA.

Morahan-Martin, J.M., 2004. How Internet users find, evaluate, and use online health information: a cross-cultural review. CyberPsychology and Behavior 7, 497-510.

Mossberger, K., Tolbert, C.J., Stansbury, M., 2003. Virtual Inequality: Beyond the Digital Divide. Georgetown University Press, Washington, DC.

Ono, H., Zavodny, M., 2003. Gender and the Internet. Social Science Quarterly 84, 111-121.

Otter, M., Johnson, H., 2000. Lost in hyperspace: metrics and mental models. Interacting with Computers 13, 1-40.

Pan, B., et al., 2007. In Google we trust: users' decisions on rank, position, and relevance. Journal of Computer-Mediated Communication 12 (3).

Park, J, Kim, J., 2000. Contextual navigation aids for two World Wide Web systems. International Journal of HumanComputer Interaction 12, 193-217.

Pritchard, A., Cartwright, V., 2004. Transforming that they read: helping eleven-year-olds engage with Internet information. Literacy 38, 26-31.

Renahy, E., Parizot, I., Chauvi, P., 2008. Health information seeking on the Internet: a double divide? BMC Public Health 8 (1), 69.

Shneiderman, B., Byrd, D., Croft, B., 1997. Clarifying search: a user-interface framework for text searches. D-Lib Magazine. Retrieved January 2010 from http://www.dlib.org/dlib/january97/retrieval/01shneiderman.html.

Schumacher, P., Morahan-Martin, J., 2001. Gender, Internet and computer attitudes and experiences. Computers in Human Behavior 17, 95-110.

Søby, M., 2003. Digital Competences: From ICT Skills to Digital Bildung. University of Oslo Press, Oslo.

Spink, A., Wolfram, D., Jansen, B.J., Saracevic, T., 2001. Searching the web: the public and their queries. Journal of the American Society for Information Science 53, 226-234.

Steyaert, J., 2002. Inequality and the digital divide: myths and realities. In: Hick, S., McNutt, J. (Eds.), Advocacy, Activism and the Internet. Lyceum Press, Chicago, pp. 199-211.

Talja, S., 2005. The social and discursive construction of computing skills. Journal of the American Society for Information Science and Technology 56, 13-22.

Van Deursen, A.J.A.M., Van Dijk, J.A.G.M., 2009. Using the Internet: skill related problems in users' online behavior. Interacting with Computers 21, 393-402.

Van Deursen, A.J.A.M., Van Dijk, J.A.G.M., 2010. Measuring Internet skills. International Journal of Human Computer Interaction 26, 891-916.

Van Deursen, A.J.A.M., Van Dijk, J.A.G.M. Internet skills and the digital divide. New Media and Society, doi:10.1177/ 1461444810386774 , in press.

Van Dijk, J., 2005. The Deepening Divide: Inequality in the Information Society. Sage, London.

Van Dijk, J., Hacker, K., 2003. The digital divide as a complex and dynamic phenomenon. The Information Society 19 , 315-327.

Virkus, S., 2003. Information Literacy in Europe: A Literature Review. Information Research 8, Paper No. 159.

Warschauer, M., 2003. Technology and Social inclusion: Rethinking the Digital Divide. The MIT Press, Cambridge, MA.

Wasserman, I.M., Richmond-Abbott, M., 2005. Gender and the Internet: causes of variation in access, level, and scope of use. Social Science Quarterly 86, 252-270.

Witte, J.C., Mannon, S.E., 2009. The Internet and Social Inequalities. Routledge, New York.

Alexander J.A.M. van Deursen is an assistant professor at the University of Twente in the Netherlands. His dissertation, entitled 'Internet skills, vital assets in an information society' has just been released. His research focuses on digital inequality with specific attention to Internet skills.

Jan A.G.M. van Dijk is Professor of Communication Science and the Sociology of the Information Society at the University of Twente, the Netherlands. He is chair of the Department of Media, Communication and Organization and Director of the Center for eGovernment Studies at the same university.

Oscar Peters $(\mathrm{PhD})$ is Managing Director at the IBR Research Institute for Social Sciences and Technology at the University of Twente, The Netherlands. His research interests are (mass) media use and effects, in particular the positive and negative effects of video game play and the adoption and use of new media and ICT, with a special interest in the adoption of ambient technologies. 